\title{
Infectious complications in OIF/OEF veterans with traumatic brain
} injury

\author{
Birgitt Dau, MD; ${ }^{1-2}$ Gina Oda, MS; ${ }^{3}$ Mark Holodniy, MD $^{1-3^{*}}$ \\ ${ }^{1}$ Department of Veterans Affairs (VA) Palo Alto Health Care System, Palo Alto, CA; ${ }^{2}$ Division of Infectious Diseases, \\ Stanford University, Stanford, CA; ${ }^{3}$ Office of Public Health Surveillance and Research, VA, Washington, DC
}

\begin{abstract}
Of veterans from the U.S. Global War on Terrorism who have sought care in the Department of Veterans Affairs, approximately $12 \%$ have an infectious disease diagnosis. Infections in those veterans with traumatic brain injury (TBI) include infections associated with blast injuries and burns, such as skin and soft tissue infections; infections as a result of retained bullet or shrapnel fragments; pulmonary infections resulting from lung injury, intubation, or resultant tracheostomy; hospital-acquired infections, such as those associated with methicillin-resistant Staphylococcus aureus and other antimicrobial resistant organisms such as Acinetobacter baumannii; and infections from implanted prosthetic devices, such as metal hardware or skull flaps. Longer-term cognitive impairment may result in behaviors that place veterans with TBI at risk for human immunodeficiency virus or hepatitis C virus infections. Finally, chronic infections acquired abroad, such as cutaneous leishmaniasis or Q-fever, may be diagnosed after veterans return to the United States. These infections present challenges in terms of added morbidity and costs associated with complex antimicrobial management; isolation requirements; and surgical procedures, such as those to remove infected retained fragments or prosthetic devices. In this review, providers will become more familiar with the scope and complexity of infectious disease management in veterans with TBI.
\end{abstract}

Key words: Acinetobacter, Afghanistan, brain injury, infection, infectious disease management, Iraq, leishmaniasis, MRSA, sexually transmitted infection, veteran.

\section{INTRODUCTION}

More than 1 million Active Duty personnel have served in Operation Iraqi Freedom (OIF) and Operation Enduring Freedom (OEF) in the Global War on Terrorism. Of those, more than 347,000 have sought care in Department of Veterans Affairs (VA) medical centers since 2003. Approximately 12 percent have sought care associated with an infectious disease-related problem (Table 1). Although data are still emerging, no complete

\footnotetext{
Abbreviations: $\mathrm{CRP}=\mathrm{C}$-reactive protein, $\mathrm{CT}=$ computed tomography, DOD = Department of Defense, ESR = erythrocyte sedimentation rate, GNO = gram-negative organism, GPO = gram-positive organism, HIV = human immunodeficiency virus, IED = improvised explosive device, LRMC = Landstuhl Regional Medical Center, MDR = multidrug-resistant, MRSA = methicillin-resistant Staphylococcus aureus, OEF = Operation Enduring Freedom, OIF = Operation Iraqi Freedom, OR = operating room, PEEK = polyetheretherketone, $\mathrm{STI}=$ sexually transmitted infection, TBI = traumatic brain injury, VA = Department of Veterans Affairs, VAPAHCS = VA Palo Alto Health Care System, WRAMC $=$ Walter Reed Army Medical Center.

*Address all correspondence to Mark Holodniy, MD; VA Palo Alto Health Care System, 3801 Miranda Ave (132), Palo Alto, CA 94304; 650-852-3408; fax: 650-858-3978. Email: mark.holodniy@va.gov, holodniv@stanford.edu DOI:10.1682/JRRD.2008.09.0113
} 
Table 1.

Diagnoses by broad ICD-9 categories for OIF/OEF veterans evaluated at VA healthcare facility during fiscal years 2002-2008, second quarter.

\begin{tabular}{|c|c|c|}
\hline \multirow{2}{*}{ Diagnosis (ICD-9 Category) } & \multicolumn{2}{|c|}{ OIF/OEF Veterans $(N=347,750)$} \\
\hline & Frequency $^{\dagger}$ & Percent \\
\hline Infectious and Parasitic Diseases (001-139) & 40,956 & 11.78 \\
\hline Benign Neoplasms (210-239) & 13,910 & 4.00 \\
\hline Diseases of Endocrine/Nutritional/Metabolic Systems (240-279) & 75,850 & 21.81 \\
\hline Diseases of Nervous System/Sense Organs (320-389) & 121,473 & 34.36 \\
\hline Diseases of Circulatory System (290-459) & 56,900 & 16.36 \\
\hline Diseases of Respiratory System (460-519) & 71,087 & 20.44 \\
\hline Diseases of Digestive System (520-579) & 110,449 & 31.76 \\
\hline Injury/Poisonings (800-900) & 73,767 & 21.21 \\
\hline \multicolumn{3}{|c|}{$\begin{array}{l}{ }^{*} \text { Hospitalizations and outpatient visits recorded as of March } 31,2008 . \\
{ }^{\dagger} \text { Veterans can have multiple diagnoses with each healthcare encounter. A veteran is counted only once in any single diagnostic category but can be counted in mul- } \\
\text { tiple categories. } \\
\text { ICD-9 = International Classification of Diseases-9th Revision, OIF/OEF = Operation Iraqi Freedom/Operation Enduring Freedom, VA = Department of Veterans Affairs. }\end{array}$} \\
\hline
\end{tabular}

accounting exists of the types of infections that may be associated with exposures in Afghanistan and Iraq. This article will review what is currently known about infections that military personnel have been exposed to while overseas and what additional risks are posed after these personnel return to the United States. We first present two case reports of OIF/OEF veterans who experienced traumatic brain injury (TBI) during their service and subsequently developed infectious complications related to this injury. These cases help illustrate the complexity of the infections these veterans face, including infections of prosthetic material placed for treatment of trauma-related injuries; multidrug-resistant (MDR) infections acquired during medical care; and susceptibility to infection because of prevalent factors, such as a veteran's altered mental status or a practitioner's use of invasive medical devices. We then provide a summary of infections in OIF/OEF veterans treated in the polytrauma unit at the VA Palo Alto Health Care System (VAPAHCS), one of four VA polytrauma units in the country treating injured OIF/OEF veterans. Finally, we review the literature on trauma-related infections and other infections that veterans may be exposed to while in service overseas.

\section{CASE PRESENTATIONS}

\section{Case 1}

This patient was a 33-year-old OIF veteran who experienced blast injuries as a result of an improvised explosive device (IED) in Iraq. He had a TBI and subarachnoid hemorrhage, multiple fractures, and a splenic laceration. He underwent an exploratory laparotomy at a Baghdad field hospital and was subsequently airlifted to Walter Reed Army Medical Center (WRAMC) in Washington, DC. At WRAMC, he underwent cranial bolt placement, tracheostomy placement, and multiple other procedures. His treatment at WRAMC was complicated by nosocomial Pseudomonas aeruginosa bacteremia and pneumonia. He was eventually stabilized and transferred to the intensive care unit at the VAPAHCS about 6 weeks after his initial injury. On presentation, he was febrile, tachycardic, hypoxemic, and comatose. A head computed tomography (CT) scan revealed cerebral edema. A chest $\mathrm{X}$-ray did not demonstrate any evidence of pneumonia. He was started empirically on meropenem, ciprofloxacin, and vancomycin. The tracheal aspirate and urine cultures grew Pseudomonas aeruginosa that was resistant to imipenem, and a blood culture grew Staphylococcus epidermidis. His 
regimen was changed to piperacillin-tazobactam and vancomycin, after which his condition improved and he was transferred to the TBI unit. He remained afebrile, and subsequent urine and blood cultures were negative. However, he developed low-grade fevers and repeat tracheal aspirate cultures revealed Pseudomonas aeruginosa and $>10$ (5) Candida albicans in his urine, requiring retreatment with piperacillin-tazobactam and fluconazole.

\section{Case 2}

This patient was a 25-year-old Army corporal who experienced a penetrating IED blast injury in Iraq that affected the right temporal, parietal, and left frontal lobes. He underwent a craniectomy with partial right temporal and parietal lobectomy. He was transferred to Landstuhl Regional Medical Center (LRMC) in Landstuhl, Germany, where he developed right lower-lobe pneumonia and was treated with ampicillin-sulbactam and vancomycin. He was then transferred to the National Naval Medical Center in Bethesda, Maryland. He continued to have fever, and sputum culture grew MDR Acinetobacter baumannii that was treated with levofloxacin and meropenem. He was transferred to WRAMC, where he developed Enterococcus faecalis bacteremia and was treated for 2 weeks with ampicillin. He subsequently developed increased brain swelling and a ventriculoperitoneal shunt was placed.

Two weeks later, he was transferred to the polytrauma unit at VAPAHCS. His rehabilitation was uneventful except for the development of a urinary tract infection with an Enterococcus species that was successfully treated with ampicillin for 10 days. He was doing well overall and showed neurological improvement, with the ability to follow commands and move his left side. He was therefore taken to the operating room (OR), where an artificial bone flap made of polyetheretherketone (PEEK) polymer was placed to repair the large right skull defect. One month after cranial implant placement, he developed fever, tenderness over the skull flap, and elevated white blood cell count. A subgaleal fluid collection was noted on a CT scan. Aspirated fluid grew methicillinresistant Staphylococcus aureus (MRSA). Vancomycin, ceftriaxone, and rifampin were begun. Although the fluid contained MRSA, whether the underlying prosthetic bone flap was also infected was unclear. However, C-reactive protein (CRP) and erythrocyte sedimentation rate (ESR) values were markedly elevated at $15 \mathrm{mg} / \mathrm{L}$ and $65 \mathrm{~mm} / \mathrm{h}$, respectively.
After 1 week on antimicrobial therapy, the patient demonstrated a decline in mental status and significant new erythema, tenderness, and swelling on his scalp, suggesting worsening of his infection. He underwent incision and drainage with removal of the flap 3 months after its initial placement. Cultures of underlying tissue grew MRSA. He received 6 weeks of vancomycin treatment and CRP and ESR values normalized. He continued with his rehabilitation program for 9 months, after which he underwent a repeat right cranioplasty with a new PEEK implant. Postoperatively, the patient was not responsive and an emergent head CT scan showed diffuse malignant brain swelling with effaced basal cisterns and loss of gray/white matter differentiation and low density changes in both basal ganglia. Examination showed no extremity movement, and the left pupil was fixed and dilated. He was brought to the OR emergently for removal of the right cranioplasty, left decompressive craniectomy, and bilateral duroplasty. He was brought to the intensive care unit where, despite maximal resuscitative efforts, he died.

\section{REVIEW OF VAPAHCS-ASSOCIATED INFECTIONS AMONG OIF/OEF VETERANS}

These two cases demonstrate the increasing complexity of infectious disease management in OIF/OEF veterans with TBI. Infections may be acquired at the time of injury overseas or during transit through various healthcare facilities before arrival at a VA facility, such as was seen in case 1 with MDR Pseudomonas pneumonia. Despite the patient's treatment at Department of Defense (DOD) facilities, the organism and underlying infection persisted after the patient's arrival at the VA facility. Presence of a tracheostomy can also lead to persistent colonization of the airway, and cognitive dysfunction secondary to TBI can lead to difficulty handling secretions, resulting in pulmonary infections. Complications of urinary catheterization and repeated antibacterial therapy can lead to yeast infections.

In case 2, the patient acquired pneumonia secondary to MDR Acinetobacter infection at a DOD facility before arrival at the VA facility. This patient also developed an Enterococcus urinary tract infection while hospitalized at the VA, likely the result of local acquisition. He subsequently developed a prosthetic skull flap MRSA infection, necessitating removal of the flap. Prior documented 
nasal MRSA colonization may have been a risk factor for this subsequent infection.

As stated previously, national-level data are not available for determining the specific prevalence or trends of OIF/OEF infections over time. A review of polytrauma cases at VAPAHCS is helpful in describing the infections being seen in this population, but the number of infections is small and may not represent other VA or outside healthcare centers. Our review of TBI infections was approved by the Stanford University Institutional Review Board. From January 2002 through October 2007, 180 OIF/OEF veterans received inpatient care at the VAPAHCS Polytrauma Rehabilitation Center. Microbiology records were reviewed for date, body source, and organism. Duplicate isolates and repeat cultures that had the same isolates within 30 days were eliminated. Of the inpatients, 35 of 180 (19\%) had or developed 137 unique infections while hospitalized. Urinary tract isolates were the most common $(n=36,26 \%)$, followed by sputum ( $n=31,23 \%)$, wound $(n=25,18 \%)$, and blood ( $n=21,15 \%)$. A total of 21 different organisms were recovered; gram-negative organisms (GNOs) were more common than gram-positive organisms (GPOs). Many of the infections were polymicrobial. Pseudomonas was the most commonly isolated organism (19\% of isolates), followed by coagulase-negative Staphylococcus (15\%), MRSA (10\%), methicillin-sensitive Staphylococcus aureus (9\%), and Klebsiella pneumoniae (9\%). Fully 52 percent of Escherichia coli and Klebsiella pneumoniae isolates were extended-spectrum $b$-lactamase producers (Table 2). GNOs were likely to be recovered from urine and sputum cultures, whereas GPOs like MRSA and other staphylococcal species were found in wound and bloodstream infections.

\section{TRAUMA-RELATED AND ACINETOBACTER INFECTIONS}

As illustrated by the two case studies, many of the infections incurred by OIF/OEF personnel are traumarelated. The in-action wounds are caused by high-velocity projectiles (shrapnel, gunshot); blast devices; and burns, primarily to the extremities ( $65 \%$ ), head and neck ( 15\%), thorax ( 10\%), and abdomen ( 7\%) [1]. TBI may necessitate neurosurgical procedures, including placement of prosthetic material such as wire mesh or titanium plates. Such procedures can result in meningitis and prosthetic-device infections [2].

Cultures of battlefield wounds at the time of injury primarily recover GPOs, but when infections develop, they are caused by GNOs [3-5]. Likewise, trauma-associated acute osteomyelitis in OIF/OEF veterans is caused predominantly by GNOs, though GPOs are more often found during recurrences [6]. Many of these GNOs, including Acinetobacter species, are MDR, making treatment challenging [7]. Starting in 2003, increased Acinetobacter baumannii infection was seen in OIF/OEF patients at military medical facilities [8].

Research on the origin of this Acinetobacter outbreak found that preexisting colonization of U.S. patients is an unlikely source of Acinetobacter infection, because strains colonizing nondeployed U.S. Army soldiers are not related to those causing infection in injured soldiers [9]. A study of the 2003 Acinetobacter outbreak in the U.S. military healthcare system found that only 2 percent of U.S. patients but 11 percent of Iraqi patients were colonized with Acinetobacter [10]. The higher rates of Acinetobacter infection and colonization in Iraqi patients could be associated with longer lengths of hospitalization [11-13] or other unknown factors. Indeed, hospitals were found to be a reservoir for Acinetobacter. After the 2003 Acinetobacter outbreak, an investigation found Acinetobacter extensively contaminating seven field hospitals in Iraq and Kuwait. These environmental strains were related to strains found in patients located at U.S. military hospitals, WRAMC, and LRMC, suggesting nosocomial transmission. Further epidemiological studies are needed to confirm these associations.

The major challenge in treating Acinetobacter infections is that most strains are MDR. These isolates have varying susceptibilities to carbapenems, such as imipenem, and the alternative, colistin, is associated with significant toxicities. In a series of wounded-in-action soldiers aboard the U.S.S. Comfort, 100 percent of Acinetobacter isolates were susceptible to imipenem [11]. However, $>80$ percent of all isolates were resistant to every one of the other antibiotics tested, including amikacin, gentamicin, ampicillin/sulbactam, ciprofloxacin, and third-generation cephalosporins. A Centers for Disease Control and Prevention report of Acinetobacter infections at LRMC and WRAMC found the following susceptibility rates: imipenem $=87$ and 82 percent, respectively; amikacin $=80$ and 48 percent; ampicillin/ sulbactam $=8$ and 35 percent; cefipime 0 and 22 percent; 
Table 2.

Top five isolated organisms by site cultured from 180 OIF/OEF veterans hospitalized at VAPAHCS from January 2002 to October 2007.

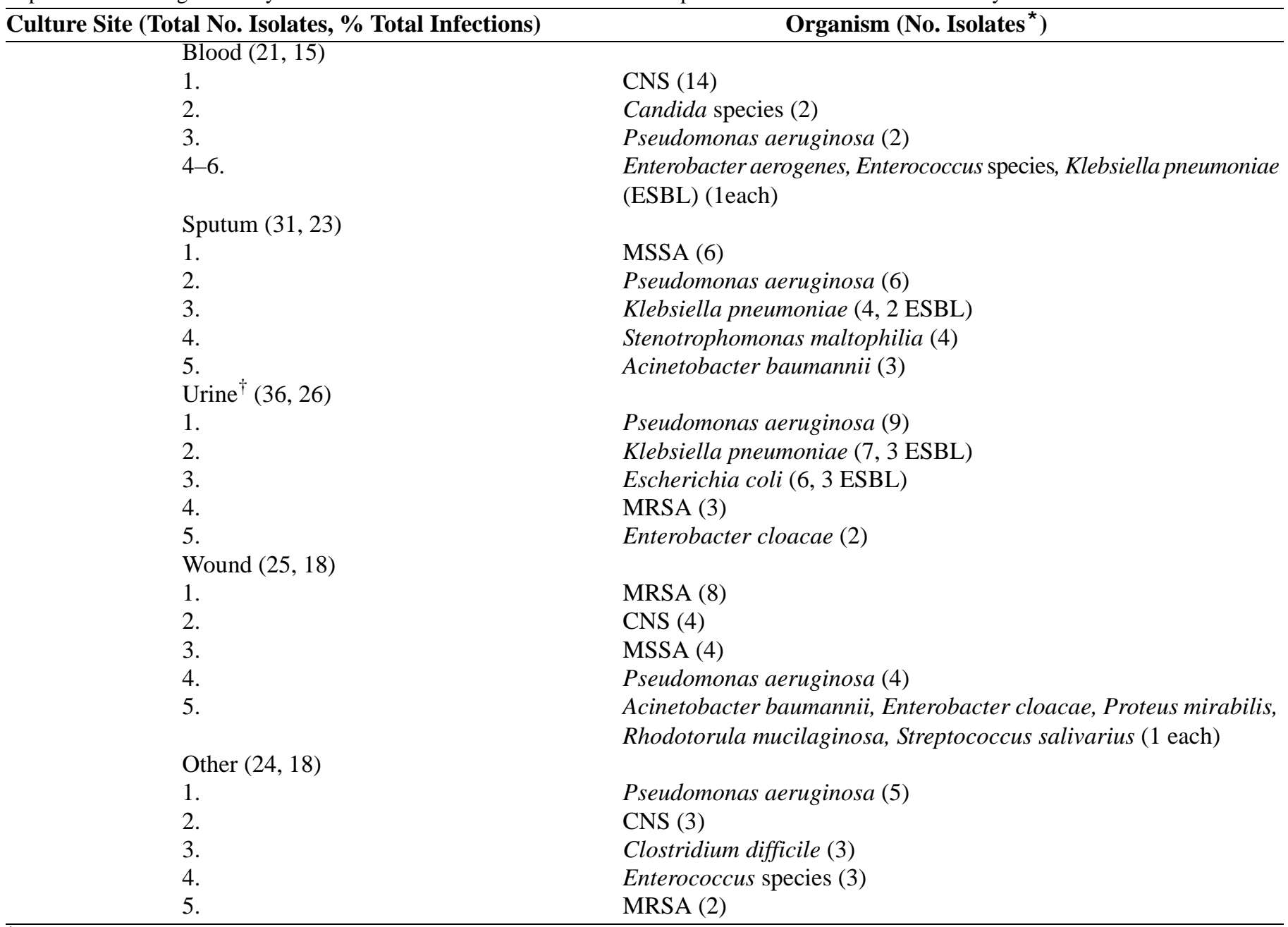

* Top five organisms only; therefore, number may not match total number in left column.

${ }^{\dagger}$ One urine culture was positive for Acinetobacter.

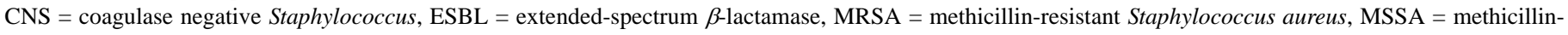

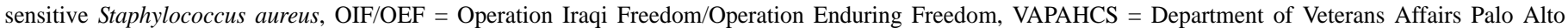
Health Care System.

and ciprofloxacin $=3$ and 20 percent. In these studies, colistin (polymyxin E) susceptibility was not tested; it is not standard in many laboratories. Another study compared imipenem and colistin susceptibilities in 23 soldiers at Brooke Army Medical Center (Fort Sam Houston, Texas) who were returning from Iraq with wound and bone Acinetobacter infections [14]. Only 89 percent of isolates were susceptible to imipenem, but 100 percent were susceptible to colistin. Therefore, colistin remains the treatment of choice for MDR Acinetobacter resistant to carbapenems and has shown clinical success in this setting [8]. At Brooke Army Medical Center, only 66 per- cent of Acinetobacter isolates in deployed personnel were imipenem susceptible, compared with 87 percent in nondeployed personnel [7]. Fortunately, $>95$ percent of the isolates were susceptible to colistin, polymyxin B, and minocycline [7]. However, intravenous minocycline is not available in the United States. [1]. Clinicians in the United States need to be aware of possible Acinetobacter resistance to carbapenems in returning OIF/OEF veterans.

Of further clinical importance, Acinetobacter has not been a highly virulent organism in wound or bone infections. Of the 48 positive cultures in the Brooke Army Medical Center study, no recurrent infections occurred 
during a mean follow-up of 9 months after dual therapy for osteomyelitis (usually amikacin plus imipenem) or monotherapy for wound infection [14]. Given the often limited antibiotic choices for treating Acinetobacterassociated infection and the potentially significant side effects of colistin therapy, especially nephrotoxicity, it is incumbent on clinicians to differentiate between Acinetobacter colonization and infection and thereby avoid unnecessary treatments.

Burns are an important cause of morbidity in OIF/ OEF patients, comprising about 5 percent of all casualties [15]. Burn patients are susceptible to bacteremia because of skin breakdown and infections associated with critical care. Of the 1,258 burn patients at the U.S. Army Institute of Surgical Research (Fort Sam Houston, Texas) from 2003 to 2006, 129 (10\%) had bacteremia and bacteremia was associated with increased mortality [16]. OIF/ OEF patients were more likely to be bacteremic than other burn patients. The most common pathogens were Pseudomonas aeruginosa, Klebsiella pneumoniae, Acinetobacter, and Staphylococcus. Seventy-one percent of Klebsiella pneumoniae isolates and sixty-seven percent of Acinetobacter isolates were MDR. Among bacteremic patients, Acinetobacter was not associated with increased mortality over other organisms but Klebsiella pneumoniae was.

Attention needs to be focused on prevention of nosocomial transmission of MDR GNOs early in a patient's treatment at field hospitals in Iraq and Afghanistan and later once the patient arrives in the United States [17]. Such prevention is important for the protection of U.S. servicemembers returning from abroad, as well as for the patients and staff they come into contact within U.S. hospitals, where these organisms can infect patients who are critically ill or immunosuppressed, causing increased mortality [18]. Wound-care techniques can help prevent wound infections. These techniques include use of wound vacuum-assisted closure and delayed primary closure of wounds [19-20]. Topical 5 percent mafenide acetate solution (5\% Sulfamylon Solution) was found to be bactericidal against many nosocomial Acinetobacter isolates, and wound-care protocols suggest its use in place of normal saline for washing wounds [21]. Other successful preventive infection-control measures include strict hand washing and restricted use of cephalosporin and cephamycin antibiotics that promote resistance in Acinetobacter [22].
We found few Acinetobacter infections at the VAPAHCS, which may reflect the changing epidemiology of Acinetobacter infections in OIF/OEF veterans or successful treatment of Acinetobacter infection closer to the time of acquisition in Afghanistan or Iraq. However, we found many infections with MDR organisms, and the lessons in infection control and appropriate antibiotic use learned from the study of Acinetobacter infections in OIF/OEF personnel can still be applied.

\section{LEISHMANIASIS}

Leishmaniasis is a protozoal infection in OIF/OEF soldiers caused by the bite of an infected sand fly. It has occurred more frequently in OIF/OEF soldiers (522 confirmed cases between August 2002 and February 2004) than in Operation Desert Storm soldiers (31 reported cases in 697,000 deployed U.S. troops) [23-24]. An anonymous survey of 15,000 troops from 2003 to 2004 found that 2.1 percent had received a diagnosis of leishmaniasis [25]. In 2005, the number of cutaneous leishmaniasis cases diagnosed at WRAMC was decreasing, possibly related to reduced sand fly bites as a result of improved shelters and insect repellent and treatment in theater with thermotherapy or oral azoles [26]. The most common manifestation is cutaneous leishmaniasis, which results in an ulcerating skin lesion that often heals spontaneously in 7 to 12 months [27]. Visceral leishmaniasis is a systemic form of the disease that can present more than a year after exposure with fever, hepatosplenomegaly, cytopenias, and hypergammaglobulinemia. Mucocutaneous leishmaniasis involves the naso-oropharyngeal mucosa and is found primarily in South America. The vast majority of leishmaniasis cases in OIF/OEF soldiers are cutaneous, although a couple cases of visceral leishmaniasis have been reported [8]. Leishmaniasis can remain asymptomatic for long periods in healthy individuals, making transmission via blood donation from returning OIF/OEF veterans a possibility [28].

Diagnosis of cutaneous leishmaniasis involves unroofing the eschar and taking a scraping of the ulcer base, performing a tissue biopsy to look for amastigotes, or culturing the material for the Leishmania parasite. If the culture is positive, molecular techniques can identify the species [27]. If the species is Leishmania major, treatment may not be required; however, systemic therapy is recommended if the lesion is in an area that is cosmetically 
sensitive or of great functional significance, if there is local dissemination, or if the lesion is larger than $4 \mathrm{~cm}$ [27]. Leishmania tropica has a more chronic course and greater incidence of complications. Leishmania major has been the etiologic organism in the vast majority of cases from Iraq, and Leishmania tropica, major, and infantum-donovani have all been identified in cases from Afghanistan [4]. Treatment includes systemic therapy with oral azoles or pentavalent antimony, cryotherapy, thermosurgery, or topical antibiotics [27].

\section{DIARRHEAL DISEASES}

Acute diarrheal syndromes have been a major source of illness during service overseas, affecting 76.8 percent of OIF troops [29]. Acute diarrhea is caused by pathogens such as Norovirus, Shigella, enterotoxigenic Escherichia coli, Salmonella, and Cryptosporidium [30-31]. Most of these acute diarrheal illnesses have resolved by the time a soldier is in U.S.-based medical care. However, some diarrheal illnesses acquired overseas can be chronic and will present to U.S. medical facilities. Giardia, Cryptosporidium, and Entamoeba histolytica should be considered in such cases [4].

\section{OTHER ENDEMIC DISEASES}

Other acute infections acquired overseas can include malaria, Q-fever, arboviral infections, and sexually transmitted infections (STIs). Cases of active tuberculosis have been negligible, though the deployment-associated skin test conversion rate is significant at 2.5 percent [4]. In 2004, 14 cases of malaria, mostly Plasmodium vivax, were acquired in Central Asia and the Middle East; 60 cases were identified during OIF from 2000 to 2005 [3233]. An outbreak of Plasmodium vivax was reported in a Ranger Task Force deployed to eastern Afghanistan [34]. Plasmodium vivax can have a delayed presentation, so many of these cases were diagnosed in the United States. Although brucellosis is endemic in Iraq and Afghanistan, only three cases were reported from 2003 to 2005 [4].

\section{SEXUALLY TRANSMITTED INFECTIONS}

STIs are transmitted in the active duty military population and are an important cause of morbidity, especially in female soldiers of reproductive age [35]. In a study of female U.S. soldiers in Kuwait from 2003 to 2004, STIs were found in about 2.5 percent of gynecologic office visits. The most prevalent STIs were genital herpes (29.5\%), Condyloma acuminata (25.0\%), and Chlamydia trachomatis (20.5\%) [35]. Twenty-one soldiers acquired human immunodeficiency virus (HIV) infection during deployment between October 2001 and July 2005 [36]. After skin infection, STIs were the most common infection for which OIF/OEF veterans sought care in the VA (Table 3). Therefore, STIs must not be overlooked during evaluation of soldiers returning from deployment.

\section{DISCUSSION}

Numerous published reports describe Acinetobacter infections in Active Duty personnel. Although Acinetobacter infections have been seen in VA facilities for years, the recent influx of hospitalized Active Duty personnel and recent veterans in VA polytrauma units presents new challenges in terms of antimicrobial and infection-control management. Only five infections (4\%) in OIF/OEF veterans on our polytrauma unit were due to Acinetobacter. Although Acinetobacter strains recovered from OIF/OEF veterans are routinely resistant to penicillins, cephalosporins, and quinolones, these Acinetobacter isolates, in general, retain their susceptibility to carbapenems and aminoglycosides. The VA national Infectious Diseases Program Office sent an information letter to VA medical centers in 2004 alerting staff about Acinetobacter infections in returning veterans [37]. Our current medical center policy requires contact precautions and isolation of patients with active Acinetobacter infections. However, when patients harboring this organism move within the facility, they could be the source of further transmission within the hospital environment. In addition, contact isolation can present problems with social isolation and stigmatization for these patients. Although, in general, infections with Acinetobacter are successfully treated in the majority of patients, determining which patients are no longer colonized with this organism may be difficult. It is important that polytrauma unit personnel work with infection control practitioners to ascertain requirements for isolation.

More than 1,000 Active Duty personnel who were bitten by sand flies have acquired cutaneous Leishmania infections. The VA recently issued an information letter 
Table 3.

Infectious disease diagnoses among OIF/OEF veterans who sought care in VA during fiscal years 2002-2008, second quarter.

Disease Category (ICD-9 Code) No. OIF/OEF Veterans

Dermatophytosis (110)

Other Diseases Due to Viruses and Chlamydiae (78)

Herpes Simplex (054)

Dermatomycosis (111)

Other Venereal Diseases (099)

Viral Infections in Conditions Classified Elsewhere and Unspecified (079)

Bacterial Infections in Conditions Classified Elsewhere and of Unspecified Site (041)

Candidiasis (112)

Viral Hepatitis (070)

Streptococcal Sore Throat and Scarlet Fever (034)
$(N=347,750)$

14,387

7,702

4,345

3,288

2,554

2,393

2,046

1,696

1,579

840

*Hospitalization and outpatient visits recorded as of March 31, 2008.

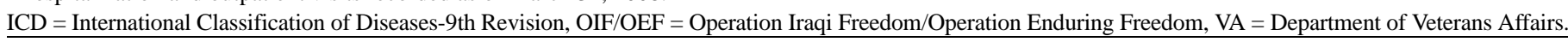

to inform VA practitioners of presentation, diagnosis, and treatment options [38]. Although veterans evaluated in VA medical centers are less likely than those in DOD facilities to present with this infection, nonhealing skin lesions of several weeks' duration should raise suspicion of Leishmania major infection. Appropriate skin scrapings or biopsy should be obtained before institution of antimicrobial therapy. Treatment is potentially complicated and prolonged and should only be instituted after consultation with an infectious disease specialist.

Many hospitalized OIF/OEF patients are either colonized or have active infections with MRSA. At our facility, systematic MRSA surveillance has now been initiated, although we do not yet know what the MRSA carriage rate is for OIF/OEF veterans, particularly those who are transferred from other medical facilities. Colonization can be acquired at DOD or VA facilities or in the community and result in subsequent infections. In 2007, the VA published a directive that requires a comprehensive MRSA surveillance program [39]. This policy requires a full-time MRSA coordinator at each VA facility, nasal swab for MRSA of all patients on admission and again on transfer and discharge, hand hygiene education for all providers, contact or barrier precautions for colonized patients, and treatment or decolonization if appropriate. This new directive will affect OIF/OEF veterans hospitalized at any VA facility.

Many injured veterans have retained shrapnel or bullet fragments. Others have various metallic orthopedic fixation or prosthetic devices. All these foreign objects may become infected with drug-resistant organisms secondary to ongoing open wounds, polyanti-microbial use, and additional surgical or radiological procedures. Prosthetic infections could also arise from inadequate sterile processing, as in a report of prosthetic skull flaps that were not appropriately sterilized before implantation [40]. These infections are difficult to manage, because a cure is unlikely without hardware removal and lengthy antimicrobial treatment. Each case requires a unique treatment plan, and infectious disease consultation is strongly advised. We found no systematic evaluation of prosthetic device infections in OIF/OEF personnel, though we know that those with orthopedic device infections were more likely to have recurrent infection than those without such devices (26\% vs 5\%, respectively) [6].

Although the majority of OIF/OEF veterans nationally have presented to the VA with skin infections, a significant minority have presented with STIs (Table 3). Behaviors associated with alcohol abuse, psychiatric illness, and TBI may put military personnel at risk of STIs, including HIV and hepatitis $\mathrm{C}$ virus, either while in service overseas or at home. TBI may predispose veterans to impulsive behaviors and poor-quality decision making that could put them at risk for STIs [41]. The high rates of hazardous alcohol use [42-43] and psychiatric illness [44-45] may also increase risk of STIs [46-47]. With the recent report of new HIV infection in Active Duty OIF personnel [36], practitioners will certainly continue to see these infections in the future. Given the already high prevalence of HIV infection in the VA [48], routine HIV screening for all veterans and risk-reduction education are recommended.

Because OIF/OEF veterans may be exposed to various viral, parasitic, fungal, and bacterial pathogens, we 
do not know what additional infections might be manifested in the future as a result of exposure during OIF/ OEF. Veterans from previous conflicts were exposed to parasites or fungal organisms while serving overseas and only years later, perhaps as a result of immunosuppression secondary to HIV infection or corticosteroids, developed reactive infections with Strongyloides stercolis and Penicillium marneffei [49-51].

Additionally, practitioners should be aware of potential reactions from long-term antimicrobial utilization. VA recently issued an information letter regarding the side effects of mefloquine (Lariam) for malaria prophylaxis [52]. Case reports have been published on patients who developed acute psychiatric symptoms, including suicidal ideation or posttraumatic stress disorder-like symptoms associated with mefloquine use. Because of the long half-life of this medication, patients returning on leave or recently discharged and manifesting such symptoms could have a medication-induced syndrome.

\section{SUMMARY AND CONCLUSIONS}

We were encouraged to find that only 19 percent of hospitalized OIF/OEF veterans at our facility had infections on presentation or developed infection subsequently during admission. But as the case presentations indicate, many of those infections that do develop are complex and involve MDR organisms. Infectious complications as a result of blast or projectile injury will continue to be seen in the VA until OIF/OEF combat operations cease [53]. New infections or reactivation of organisms acquired overseas could also manifest themselves once the veterans are back in the United States. Management of patients is currently challenged by prosthetic-device infections and the need for additional surgical procedures. Infections with MRSA or MDR organisms such as Acinetobacter may require patient isolation, increasing the costs associated with staffing, personal protective equipment, and complex antimicrobial regimens. The transmission of nosocomial pathogens to hospitalized civilian populations may further increase costs. As a recent VA Inspector General report indicated, all VA staff, but particularly those involved in the acute care of returning OIF/OEF veterans, should become familiar with the scope of injuries and complications associated with these veterans, including infectious disease complications [2].

\section{ACKNOWLEDGMENTS}

\section{Author Contributions:}

Study concept and design: B. Dau, M. Holodniy.

Acquisition of data: B. Dau, G. Oda.

Analysis and interpretation of data: B. Dau, G. Oda, M. Holodniy.

Drafting of manuscript: B. Dau, G. Oda.

Critical revision of manuscript for important intellectual content:

M. Holodniy.

Statistical analysis: B. Dau, G. Oda.

Administrative, technical, or material support: M. Holodniy.

Study supervision: M. Holodniy.

Financial Disclosures: The authors have declared that no competing interests exist.

Funding/Support: This material was unfunded at the time of manuscript preparation.

Additional Contributions: We would like to thank Han Kang for providing data for Tables 1 and 3.

Participant Follow-Up: The authors do not plan to inform participants of the publication of this study.

\section{REFERENCES}

1. Murray CK. Epidemiology of infections associated with combat-related injuries in Iraq and Afghanistan. J Trauma. 2008;64(3 Suppl):S232-38. [PMID: 18316967] DOI:10.1097/TA.0b013e318163c3f5

2. Department of Veterans Affairs Office of Inspector General. Healthcare inspection: Review of quality of care, Department of Veterans Affairs James A. Haley Medical Center, Tampa, Florida. Washington (DC): VA Office of Inspector General; 2005 Jun 1. Report No.: 05-00641-149.

3. Murray CK, Roop SA, Hospenthal DR, Dooley DP, Wenner K, Hammock J, Taufen N, Gourdine E. Bacteriology of war wounds at the time of injury. Mil Med. 2006;171(9): 826-29. [PMID: 17036599]

4. Aronson NE, Sanders JW, Moran KA. In harm's way: Infections in deployed American military forces. Clin Infect Dis. 2006;43(8):1045-51. [PMID: 16983619] DOI:10.1086/507539

5. Johnson EN, Burns TC, Hayda RA, Hospenthal DR, Murray CK. Infectious complications of open type III tibial fractures among combat casualties. Clin Infect Dis. 2007; 45(4):409-15. [PMID: 17638186]

DOI:10.1086/520029

6. Yun HC, Branstetter JG, Murray CK. Osteomyelitis in military personnel wounded in Iraq and Afghanistan. J Trauma. 2008;64(2 Suppl):S163-68. [PMID: 18376160]

DOI:10.1097/TA.0b013e318160868c

7. Hawley JS, Murray CK, Griffith ME, McElmeel ML, Fulcher LC, Hospenthal DR, Jorgensen JH. Susceptibility of Acinetobacter strains isolated from deployed U.S. military personnel. 
Antimicrob Agents Chemother. 2007;51(1):376-78.

[PMID: 17043112]

DOI:10.1128/AAC.00858-06

8. Centers for Disease Control and Prevention (CDC). Acinetobacter baumannii infections among patients at military medical facilities treating injured U.S. service members, 2002-2004. MMWR Morb Mortal Wkly Rep. 2004;53(45): 1063-66. [PMID: 15549020]

9. Griffith ME, Ceremuga JM, Ellis MW, Guymon $\mathrm{CH}$, Hospenthal DR, Murray CK. Acinetobacter skin colonization of US Army soldiers. Infect Control Hosp Epidemiol. 2006;27(7):659-61. [PMID: 16807838]

DOI:10.1086/506596

10. Scott P, Deye G, Srinivasan A, Murray C, Moran K, Hulten E, Fishbain J, Craft D, Riddel S, Lindler L, Mancuso J, Milstrey E, Bautista CT, Patel J, Ewell A, Hamilton T, Gaddy C, Tenney M, Christopher G, Petersen K, Endy T, Petruccelli B. An outbreak of multidrug-resistant Acinetobacter baumannii-calcoaceticus complex infection in the US military health care system associated with military operations in Iraq. Clin Infect Dis. 2007;44(12):1577-84. [PMID: 17516401]

DOI:10.1086/518170

11. Petersen K, Riddle MS, Danko JR, Blazes DL, Hayden R, Tasker SA, Dunne JR. Trauma-related infections in battlefield casualties from Iraq. Ann Surg. 2007;245(5):803-11. [PMID: 17457175] DOI:10.1097/01.sla.0000251707.32332.c1

12. Yun HC, Murray CK, Roop SA, Hospenthal DR, Gourdine E, Dooley DP. Bacteria recovered from patients admitted to a deployed U.S. military hospital in Baghdad, Iraq. Mil Med. 2006;171(9):821-25. [PMID: 17036598]

13. Griffith ME, Gonzalez RS, Holcomb JB, Hospenthal DR, Wortmann GW, Murray CK. Factors associated with recovery of Acinetobacter baumannii in a combat support hospital. Infect Control Hosp Epidemiol. 2008;29(7):664-66.

[PMID: 18547156]

DOI:10.1086/589585

14. Davis KA, Moran KA, McAllister CK, Gray PJ. Multidrugresistant Acinetobacter extremity infections in soldiers. Emerg Infect Dis. 2005;11(8):1218-24. [PMID: 16102310]

15. Wolf SE, Kauvar DS, Wade CE, Cancio LC, Renz EP, Horvath EE, White CE, Park MS, Wanek S, Albrecht MA, Blackbourne LH, Barillo DJ, Holcomb JB. Comparison between civilian burns and combat burns from Operation Iraqi Freedom and Operation Enduring Freedom. Ann Surg. 2006;243(6):786-92. [PMID: 16772782] DOI:10.1097/01.sla.0000219645.88867.b7

16. Ressner RA, Murray CK, Griffith ME, Rasnake MS, Hospenthal DR, Wolf SE. Outcomes of bacteremia in burn patients involved in combat operations overseas. J Am Coll
Surg. 2008;206(3):439-44. [PMID: 18308213]

DOI:10.1016/j.jamcollsurg.2007.09.017

17. Siegel J, Rhinehart E, Jackson M, Chiarello L, The Healthcare Infection Control Practices Advisory Committee. Management of multidrug-resistant organisms in healthcare settings, 2006. Washington (DC): Centers for Disease Control and Prevention; 2006.

18. Chen HP, Chen TL, Lai CH, Fung CP, Wong WW, Yu KW, Liu CY. Predictors of mortality in Acinetobacter baumannii bacteremia. J Microbiol Immunol Infect. 2005;38(2):127-36. [PMID: 15843858]

19. Leininger BE, Rasmussen TE, Smith DL, Jenkins DH, Coppola C. Experience with wound VAC and delayed primary closure of contaminated soft tissue injuries in Iraq. J Trauma. 2006;61(5):1207-11. [PMID: 17099530] DOI:10.1097/01.ta.0000241150.15342.da

20. Lalliss SJ, Branstetter JG, Murray CK, Ficke JR, Jenkins DH. Infection rates in U.S. military personnel using vacuumassisted closure. Plast Reconstr Surg. 2007;120(2): 574-75. [PMID: 17632372] DOI:10.1097/01.prs.0000267671.78598.b4

21. Kucan JO, Heggers JP. The potential benefit of 5\% Sulfamylon Solution in the treatment of Acinetobacter baumannii-contaminated traumatic war wounds. J Burns Wounds. 2005;4:e3. [PMID: 16921408]

22. Urban C, Segal-Maurer S, Rahal JJ. Considerations in control and treatment of nosocomial infections due to multidrugresistant Acinetobacter baumannii. Clin Infect Dis. 2003; 36(10):1268-74. [PMID: 12746772] DOI:10.1086/374847

23. Elston DM, Miller SD. Leishmaniasis acquired in the Iraqi Theater of Operations: Lessons learned. Cutis. 2004;74(4): 253-55. [PMID: 15551719]

24. Centers for Disease Control and Prevention (CDC). Update: Cutaneous leishmaniasis in U.S. military personnel—Southwest/Central Asia, 2002-2004. MMWR Morb Mortal Wkly Rep. 2004;53(12):264-65. [PMID: 15057192]

25. Mitchell AE, Sivitz LB, Black RE, editors. Gulf war and health: Volume 5. Infectious disease [Internet]. Washington (DC): The National Academies Press; 2007. Available from: http://books.nap.edu/openbook.php?record id=11765\&page=R1/.

26. Zapor MJ, Moran KA. Infectious diseases during wartime. Curr Opin Infect Dis. 2005;18(5):395-99. [PMID: 16148525] DOI:10.1097/01.qco.0000182102.50430.2c

27. Weina PJ, Neafie RC, Wortmann G, Polhemus M, Aronson NE. Old world leishmaniasis: An emerging infection among deployed US military and civilian workers. Clin Infect Dis. 2004;39(11):1674-80. [PMID: 15578370] DOI:10.1086/425747 
28. Cardo LJ. Leishmania: Risk to the blood supply. Transfusion. 2006;46(9):1641-45. [PMID: 16965594]

DOI:10.1111/j.1537-2995.2006.00941.x

29. Putnam SD, Sanders JW, Frenck RW, Monteville M, Riddle MS, Rockabrand DM, Sharp TW, Frankart C, Tribble DR. Self-reported description of diarrhea among military populations in operations Iraqi Freedom and Enduring Freedom. J Travel Med. 2006;13(2):92-99.

[PMID: 16553595] DOI:10.1111/j.1708-8305.2006.00020.x

30. Thornton SA, Sherman SS, Farkas T, Zhong W, Torres P, Jiang X. Gastroenteritis in US Marines during Operation Iraqi Freedom. Clin Infect Dis. 2005;40(4):519-25.

[PMID: 15712073]

DOI:10.1086/427501

31. Monteville MR, Riddle MS, Baht U, Putnam SD, Frenck RW, Brooks K, Moustafa M, Bland J, Sanders JW. Incidence, etiology, and impact of diarrhea among deployed US military personnel in support of Operation Iraqi Freedom and Operation Enduring Freedom. Am J Trop Med Hyg. 2006;75(4):762-67. [PMID: 17038708]

32. Malaria, U.S. Army, 2004. Medical Surveillance Monthly Report. 2005;11(1):7-10.

33. Ciminera P, Brundage J. Malaria in U.S. military forces: A description of deployment exposures from 2003 through 2005. Am J Trop Med Hyg. 2007;76(2):275-79.

[PMID: 17297035]

34. Kotwal RS, Wenzel RB, Sterling RA, Porter WD, Jordan NN, Petruccelli BP. An outbreak of malaria in US Army Rangers returning from Afghanistan. JAMA. 2005;293(2):

212-16. [PMID: 15644548]

DOI:10.1001/jama.293.2.212

Erratum in: JAMA. 2005;293(6):678.

35. Wright J, Albright TS, Gehrich AP, Dunlow SG, Lettieri CF, Buller JL. Sexually transmitted diseases in Operation Iraqi Freedom/Operation Enduring Freedom. Mil Med. 2006; 171(10):1024-26. [PMID: 17076459$]$

36. Scott P. HIV-1 infections among U.S. Army soldiers deployed to combat operations in Iraq and Afghanistan. 45th Annual Meeting of the Infectious Diseases Society of America; 2007 Oct 4-7; San Diego, CA. Arlington (VA): IDSA; 2007.

37. Roselle G. Acinetobacter baumannii. Department of Veterans Affairs Colleague's Letter; 2004. p. 539.

38. Perlin J. Guidance for the diagnosis and treatment of leishmania infection. VHA Information Letter; 2004. Letter No.: IL 10-2004-013(13).

39. Kussman MJ. Methicillin-resistant Staphylococcus aureus (MRSA) initiative. Washington (DC): Department of Veterans Affairs Veterans Health Administration; 2007 Jan 22. VHA Directive 2007-002.
40. Department of Veterans Affairs Office of Inspector General. Health care inspection: Quality of care in cranial implant surgeries at James A. Haley VA Medical Center, Tampa, Florida. Washington (DC): VA Office of Inspector General; 2006 Apr 10. Report No.: 06-01642-126.

41. Salmond CH, Menon DK, Chatfield DA, Pickard JD, Sahakian BJ. Deficits in decision-making in head injury survivors. J Neurotrauma. 2005;22(6):613-22.

[PMID: 15941371]

DOI:10.1089/neu.2005.22.613

42. Bray RM, Hourani, LL, Rae Olmsted KL, Witt M, Brown JM, Pemberton MR, Marsden ME, Marriott B, Scheffler S, Vandermaas-Peeler R. 2005 Department of Defense survey of health related behaviors among active duty military personnel [Internet]. Available from: http://oai.dtic.mil/oai/ oai?verb=getRecord\&metadataPrefix $=$ html\&identifier=ADA465678/.

43. Calhoun PS, Straits-Troster K, Kudler H. Prevalence of hazardous alcohol use and risk reduction counseling among OIF/OEF veterans. VA Health Services Research and Development (HSR\&D) National Meeting 2007; 2007 Feb 21-23; Arlington, VA. Washington (DC): HSR\&D; 2007.

44. Hoge CW, Auchterlonie JL, Milliken CS. Mental health problems, use of mental health services, and attrition from military service after returning from deployment to Iraq or Afghanistan. JAMA. 2006;295(9):1023-32.

[PMID: 16507803]

DOI:10.1001/jama.295.9.1023

45. Erbes C, Westermeyer J, Engdahl B, Johnsen E. Posttraumatic stress disorder and service utilization in a sample of service members from Iraq and Afghanistan. Mil Med. 2007;172(4):359-63. [PMID: 17484303]

46. Bryant KJ. Expanding research on the role of alcohol consumption and related risks in the prevention and treatment of HIV/AIDS. Subst Use Misuse. 2006;41(10-12):1465-1507.

[PMID: 17002990] DOI:10.1080/10826080600846250

47. Beyer JL, Taylor L, Gersing KR, Krishnan KR. Prevalence of HIV infection in a general psychiatric outpatient population. Psychosomatics. 2007;48(1):31-37. [PMID: 17209147] DOI:10.1176/appi.psy.48.1.31

48. Owens DK, Sundaram V, Lazzeroni LC, Douglass LR, Sanders GD, Taylor K, VanGroningen R, Shadle VM, McWhorter VC, Agoncillo T, Haren N, Nyland J, Tempio P, Khayr W, Dietzen DJ, Jensen P, Simberkoff MS, Bozzette SA, Holodniy M. Prevalence of HIV infection among inpatients and outpatients in Department of Veterans Affairs health care systems: Implications for screening programs for HIV. Am J Public Health. 2007;97(12):2173-78.

[PMID: 17971545] DOI:10.2105/AJPH.2007.110700 
49. Genta RM, Weesner R, Douce RW, Huitger-O’Connor T, Walzer PD. Strongyloidiasis in US veterans of the Vietnam and other wars. JAMA. 1987;258(1):49-52.

[PMID: 3586290$]$

DOI:10.1001/jama.258.1.49

50. Hakim SZ, Genta RM. Fatal disseminated strongyloidiasis in a Vietnam War veteran. Arch Pathol Lab Med. 1986; 110(9):809-12. [PMID: 3755889]

51. Carey J, Hofflich H, Amre R, Protic J, Perlman DC. Penicillium marneffei infection in an immunocompromised traveler: A case report and literature review. J Travel Med. 2005;12(5):291-94. [PMID: 16256056]
52. Hamerschlag A. Possible long-term health effects from the malarial prophylaxis mefloquine (lariam). Undersecretary for Health's Information Letter; 2004. Report No.: IL 102004-007(13).

53. Murray CK. Infectious disease complications of combatrelated injuries. Crit Care Med. 2008;36(7 Suppl):S358-64. [PMID: 18594263]

DOI:10.1097/CCM.0b013e31817e2ffc

Submitted for publication September 1, 2008. Accepted in revised form February 3, 2009. 